\title{
Where are we in the question of identity: Jordanian youth as a Model
}

\author{
Dr. Safwat Al- Rousan \\ Dept. Sociology and Social Service, Al-Balqa' Applied University \\ E-mail: safwatrousan@yahoo.com \\ P.O. Box: 1293 \\ Dr. Mohammad Al-Rousan (Corresponding author) \\ Dept. Modern History, Al-Balqa' Applied University \\ E-mail: drmrousan@yahoo.com \\ P.O. Box: 1293 \\ Dr. Yousef AL-Shurman \\ Dept. Sociology and Social Service, Al-Balqa' Applied University \\ E-mail: dr_y_al_shurman@yahoo.com
}

Accepted: July 09, 2013 Published: July 31, 2013

Doi:10.5296/jsr.v4i2.4000 URL: http://dx.doi.org/10.5296/jsr.v4i2.4000

\begin{abstract}
:
This study aimed at investigating the concept of national identity and its constituents as perceived by Jordanian youth. Its main question is about the identity we have nowadays. The study sought to understand and analyze the concept of identity and its subjective and objective constituents through the identification of the perceptions of Jordanian youth of the identity by realizing its constituents, following the approach of social field studies and through some simple statistical analyses based on a sample which consisted of (250) young university people. They were asked about national identity and its most prominent constituents through the method of international sample. After analyzing the results, the study concluded the following:
\end{abstract}

First: Jordanian youth consider identity as the perception of membership to both Jordan and the tribe and devotion to the political regime as being the protector of this identity and its connection with their living place and way of upbringing.

Second: The most prominent constituent of identity is the regional dimension with (62\%), followed by the national dimension (21\%), and finally the religions dimension (17\%).

Third: The study concluded the result that there is confusion among Jordanian youth in regard to the constituents of identity, its local and national concept and the degree of perception.

The study recommended the necessity for the preparation of joint programs between the public sector and the institutions of civil society in order to create common distributors within 
the Jordanian collective sensation for one identity that reinforces membership to both society and identity simultaneously.

Keywords: Islam, Jordan, Jordanian Youth, Arabism, National Identity.

\section{Introduction:}

Higal thinks that recognizing our self-awareness leads us directly to the realm of reality, and we cannot talk about identity without the existence of difference of opinion (Banani, 2009: 112). Antony Gidniz says: "the social conditions in which we are born and brought up until we become adults certainly leave their clear effects on our behavior. However, this does not mean that human beings are creatures with without peculiar characteristics or free will. Some people may think that we are merely the product of ready- made molds with premeditated qualities prepared for us by society. Some sociologists tend to talk about social upbringing in this sense, but this attitude is defective in more than one aspect. It is true that our interaction with other people, from cradle to grave, as it is said, forms important aspects of our personalities, the matrix of values we believe in and our patterns of behavior, but the track of social upbringing really stems from our uniqueness and feelings of freedom. Through this process, each one of us develops his perception of identity and independence in thought and action" (Gidniz, 2005: 90).

"The Arab-Islamic Culture which is open to human civilization is the essence of local and national identity of Jordanian people and one of the bases of its unity, independence and progress in the face of division, subordination, cultural invasion, with all its forms and the source of basic values which the Jordanian society tries to firmly establish by science, knowledge, sound education and good example". This was stated in the fifth article of the National Jordanian Charter formed by political, educational and popular committees in 1991. But what is the reality of this clear and magnificent text in the practiced fact of the personality of the Jordanian citizen, taking into account that society has been subjected to successive waves of changes which have affected the essence of its structures and its social and cultural systems.

The question of identity again appears around the individual, group and society. What are the cultural characteristics, behavioral modes, thinking ways and the hose of formed structures of values through history which have distinguished the members of Jordanian society from those of other peoples, taking into account that Jordan with its present borders in history has not formed a political and administrative entity separated from surrounding countries before the first world war with the establishment of the Emirate of East Jordan, when the tribe has formed the essence of Jordanian identity for decades (Khalid Fayyadh: 2020, digital Ahram).

The region and Jordan have witnessed several events and conditions which have created structural impacts on society, such as the Arab-Israeli conflict, American policies in the region, the Arab situation, especially the Egyptian, the First Gulf War, the invasion of Iraq and the reality of what is called the Arab Spring with the real changes that occurred causing real influences on both society and individuals. These events have affected, in some way or the other, the cultural identity and national one and raised a lot of questions around them. 
Jordan, until the compulsory Palestinian immigrations which started in 1948, was a homogeneous society. The Sunni Arabs formed the great majority living in peace and conformity with three important sects, namely, Christians, Circassians and Shishanis.

Although these sects did not form more than $8 \%$ of the whole population, the political and social system guaranteed all their absolute religious and social liberties throughout the formation of the Jordanian State (Mahafza, et. al., 2006: 115).

Up till the first half of the twentieth century, the social system expressed social tribal organizations because the great majority of people were from tribes and stable and unstable Bedouins.

Loyalty in them was for the tribe and its Sheikh. It was loyalty proceeding any other one including the state. The tribe or clan was not confined to Bedouins but it was one of the distinguishing marks of the social organization of villages' inhabitants and even inhabitants of Jordanian cities. consequently, it is the essential problem of national identity whose influences have extended to these days. The region of Jordan has been closest to the desert and its traditions in a way that the nature of society is that of Bedouins. On this basis, the backgrounds of society, its customs, behavior, its social values and national identity have been formed (Mahafzah and others, 2006: 116).

Later, as a result of education and the tribes' members joining military service with the rise of Jordanian institutions in addition to the successive Palestinian immigrations, contact with the world and development achievements. Which led to social changes represented in the gradual transfer of loyalty to the state and country away from the tribe. These changes have been accompanied by the beginning of the appearance of social divisions and classes in place of tribal and semi- tribal ones, the fact which increased the rhythm of social move, classes and immigration.

All this led to the domination of the city in a way that three quarters of society became city dwellers. Then came the importance of the role of institutions and rules in the daily lives of people and their interactions instead of the customs and traditions which were existing on tribal ties governed by the law of the tribe (Al-Aafeef and others, 2006: 47).

However, in spite of the rising role of the state through the institutions and rules in the lives of the individuals of Jordanian society, they have not completely replaced the tribe and its values. The case of Jordanian society is similar to that of some Arab countries in which the tribe still represents a social and political base. A lot of social activities consider it as a promoting social support in the political field in order to reach power. This is clearly evident in a lot of political and social activities, especially in the field of parliamentary elections whose basic strength or participation, for many Jordanians, depends on tribal membership. The tribal symbol as well as religious background, in many occasions, are collected. The tribal address, for political accomplishment, mostly, overcomes any other one and deeply affects the essence of individual or group sensation of identity.

\section{Study Problem:}

The international and Arabic concept of identity appeared in the sixties of the past century to attract a part of the interests of several scientific fields. Alfred Grosser, a historian, said that a few concepts about identity were expanded in a way that it became a slogan that 
could solve all problems. We have recently heard about the address of identity represented in regional, national, union and Islamic thoughts, as well as the identity policies represented in the rights of minorities in their self-destiny, or civil conflicts or autonomy. We can say that the study of identity in its essence is the study of the borders of the group with its social and cultural formation (Al-Jureibee', 2012).

Ma'loof (1999) thinks that identity is the only main membership which continues in different circumstances stronger than any other thing. For some people, it may be the country, or religion or class. But when examining present conflicts, we realize that no one membership is ultimately predominant. For example, when some people are threatened in their belief, religious membership increases representing their identity.

There have been different views of scholars and researchers in the fields of psychology and sociology, especially people of knowledge and social attitudes, relations, interaction and their impact on the individual's feelings about the concept of self and national identity. The study problem is centered around the question about which identity we have these days in light of this simultaneous confusion and contrast between the individual and the group, the group and society, the social and the cultural, the real and imaginary, the local and the Arabic, the Islamic and the human, peculiarity to generality and from the tribe to the institution and the state. A question that a group of Jordanian youth were asked in order to find out the answer or some common hints from which we can infer the required answer.

\section{Aims of the Study:}

The study aimed at identifying the following:

1- The concept of national identity and the exploration of its prominent constituents in their theoretical frame.

2- The description of this concept at the level of the real conditions of Jordanian society and its prominent constructions.

3- The perception and sensation of the concept of identity by Jordanian youth.

\section{Method and Problems:}

\section{- Study Methodology:}

The social sample survey approach and the descriptive analytical method were used in order to achieve the study aims.

\section{- Study Sample:}

The study sample consisted of (250) Jordanian students at Yarmouk University, Jordan University of Science and Technology, Al-Husn University College and Irbid Private University. They were chosen by the international sample method to conduct interviews with them. The interviews included both sexes and all study variables are shown in Table (1). 
Table (1)

Subjects' Characteristics

\begin{tabular}{|c|c|c|c|}
\hline No. & Variable & Number & Percentage \\
\hline $1-$ & $\begin{array}{l}\text { Sex: } \\
\text { Man } \\
\text { Woman }\end{array}$ & $\begin{array}{c}152 \\
98\end{array}$ & $\begin{array}{l}60.8 \% \\
39.2 \%\end{array}$ \\
\hline $2-$ & $\begin{array}{l}\text { Age: } \\
18-22 \\
23-27 \\
\text { More than } 28\end{array}$ & $\begin{array}{c}65 \\
144 \\
41\end{array}$ & $\begin{array}{c}26 \% \\
57.6 \% \\
16.4 \% \\
\end{array}$ \\
\hline $3-$ & $\begin{array}{l}\text { Academic Year: } \\
\text { First } \\
\text { Second } \\
\text { Third } \\
\text { Fourth } \\
\text { Fifth and more }\end{array}$ & $\begin{array}{l}43 \\
57 \\
49 \\
69 \\
32\end{array}$ & $\begin{array}{l}17.2 \% \\
22.8 \% \\
19.6 \% \\
27.6 \% \\
12.8 \%\end{array}$ \\
\hline 4- & $\begin{array}{l}\text { Religion: } \\
\text { Muslim } \\
\text { Christian }\end{array}$ & $\begin{array}{c}217 \\
36\end{array}$ & $\begin{array}{l}85.6 \% \\
14.4 \%\end{array}$ \\
\hline $5-$ & $\begin{array}{l}\text { Residence Area: } \\
\text { Village } \\
\text { City } \\
\text { Desert } \\
\text { Camp }\end{array}$ & $\begin{array}{c}90 \\
120 \\
26 \\
14\end{array}$ & $\begin{array}{c}36 \% \\
48 \% \\
10.4 \% \\
5.6 \%\end{array}$ \\
\hline $6-$ & $\begin{array}{l}\text { Colleges: } \\
\text { Humanitarian } \\
\text { Scientific }\end{array}$ & $\begin{array}{l}140 \\
110\end{array}$ & $\begin{array}{l}56 \% \\
44 \%\end{array}$ \\
\hline & Total & 250 & $100 \%$ \\
\hline
\end{tabular}

\section{Study Instruments:}

The study used the identity indicators which consisted of (12) items formed according to Ghassan Muneer's identity indicators in his book "Marks, Indicators and Measures of National Identity, National Identities, Global Society and Media, Dar Al-Nahdhah Al-Arabiyyah, Beirut, 2002, with modification to suit the study sample. The subjects were asked about the priorities of regional and religious dimensions in regard to their sensation of identity. The responses were dealt with by using frequencies and ratios to compare the subjects' responses results on the questionnaire results in regard to the identification of identity and its indicators and then ordering its dimensions priorities.

\section{Definition of Identity:}

There have been different views of scholars and researchers in the fields of psychology, sociology and psychological guidance, especially people of knowledge and social attitudes, social relations, social interaction and the extent of their impact on the individual's perception 
of the concept of national self-identity. There will be different views of researchers about the topic of identity separately or the topic of identity in a direct way. Horne thinks that cultural factors affect human behavior and any defect in social relations certainly causes defect in behavior. She believes that where is a connection between past experiences which may include conflicts affecting the individual's moral structure and whatever future problems he will encounter (Al-Dhahiri, 1998: 102). The individual cannot live in security and stability away from the frame of society besides the fact that the interaction with other people makes the person able to perceive his identity, value and capability to face the pressures of life. Rogers confirms in his theory about self that the individual's positive awareness without deformation of the symbols of the environmental stimuli makes him and society live in security and stability and consequently adapts himself. to its external sphere. Rogers finds connection between the individual's self-assertion and his group bearing of responsibility in order to be able to work in a serious fruitful way to assert his personality and identity in the society in which he lives (Shiltz, 1983: 261-281). Arikson, Albort and Froam pointed out the importance of identity formation in personality.

As perceived by Tony Bindit, identity in the terms of dictionary of culture and society has its relation in correspondence with the reality of a person or a group in all times and places. Identity is relating to the capability to continue to exist. The question of identity confirms the principles of unity in contrast to plurality and continuity in contrast to change and transfer( Bindit and others, 2010: 700-701). The question of identity is connected with the group and being a member of it. Collective identity puts forward the principles of unity and continuity for the group to become in harmony and to be a nation with a mission. The question of the other is relating to other existing identities with their differences. The other is existing outside our culture or group (Bindint and others, 2010: 41).

Generally, identity is relating to people's understanding of themselves and what they believe of meanings and sources of this identity such as nationality, ethnic, class and social membership. There is the individual identity and the collective one although they refer to the same meaning. Examples of collective identity are the student, the mother, the Asian and the married. These identities may be inter-related for the same person to be a Muslim engineer father. But individuals organize their lives and experiences around a basic essential identity distinguished by relative continuity across time and place (Gidniz: 90-92).

Psychologist Tajifal and a group of researchers in psychology introduced the theory of social identity. They studied the membership of the individual in social groups and the concept of the group to distinguish the common psychological relation among the group and the awareness of individuals that they have common collective identity and one collective destiny. And that the common collective awareness or common feeling of membership in the group which forms the important psychological factor in defining any human formation of blocs or social category as a group of a common identity in the psychological meaning of the concept of social identity. This theory is based on a group of assumptions. One of them is that individuals seek to achieve a specific social identity and maintain it in a positive way. They derive their identity from their membership in different types of groups and that individuals realize this membership through social classification. Social identity is the main constituent from which a group of identities are formed (religious, national, cultural, professional and 
local).

Researchers think that there is a group of factors which help in the formation of the national and local identity of the nation. The more the language is connected with peoples' culture, the more it is capable of forming and carrying the identity of the nation (Aayid, 2008: 93).

Stozwil (1993) presented a study which aimed at revealing the nature of pride and perception of national identity. The study included (15) different countries from three continents. The sample consisted of (1000) subjects from each country. The instrument was a questionnaire which included a group of values, of which was national pride. The questionnaire was designed to include four multiple choice items.

Two were positive (strongly proud and proud) and two were negative (strongly unproud and unproud). There was another neutral choice.

The results of the studies showed a high distinction in the standard of living (Germany, Sweden and Japan) in which national pride was less than the average, while in countries which used to be colonies to other countries, citizens showed a high ratio of national pride and post-independence assertion of identity.

In other countries which were defeated in the second world war, the average of pride of national identity was low, while the countries that were not defeated or militarily occupied showed a high degree of national pride. In victorious countries, citizens showed happiness and belongingness to their homeland and their feelings of nationality increased. However, educated people were less proud of their national identity than the others (Stozwil, 1983; Al-Zuheiri, 2008: 37).

Aayid (2008) presented a study about the worry of globalization and its relationship with the picture of the future and religious identity. The study aimed at measuring the variables of globalization worry, the future picture and religious identity. The sample of the study consisted of higher studies male and female students (Master and Doctoral) at Baghdad University. The researcher designed the three-variable scale. After the statistical processing of the data, the results of the study showed that higher studies students had globalization worry, future picture and religious identity. There were differences to the advantage of males and humanitarian specialization in the variable of globalization worry. There were differences to the advantage of scientific specialization in future picture variable. There were no differences in religious identity that could be attributed to the variables of sex and specialization. There was a correlative relationship between the three variables (globalization worry, future picture and religious identity) (Aayid, 2008: 133).

It is worthwhile to refer to the remarkable study by Ahmad Jamal Dhahir (1985) about Arab identity and membership. This was conducted on a sample of male and female students in the Northern Region of Jordan. He linked the study to a great group of variables and concluded that the national factor was the most prominent in connecting the identity of the subjects, then came the regional factor and after that the religious one. However, he pointed out the scattering of the subjects' identity as it was not connected with something specific in spite of the fat that the national dimension was there. Dhahir (1985) added that the Arab world has a group of identities (religious, national, regional, local and tribal). He concluded that the Arab citizen really lives the crisis of identity and the most prominent identity is that 
of the family strengthening loyalty to the state and the ruler.

\section{Jordanian Youth And Their perception of Identity:}

The study tried to develop a scale of the indicators of identity by using a scale presented by Ghassan Muneer (2002) in order to ask the subjects about their perception of the basic constituent of the identity they feel. The study tried to ask the subjects about the most important constituents and their priorities. The results came as follows:

Table (2)

\section{Identity Indicators}

\begin{tabular}{|c|l|c|c|c|}
\hline No. & \multicolumn{1}{|c|}{ Item } & Agree & Disagree & Undecided \\
\hline 1. & I am Jordanian because I was born in Jordan & $73 \%$ & $25 \%$ & $2 \%$ \\
\hline 2. & $\begin{array}{l}\text { I am Jordanian because my father and } \\
\text { grandparents are so. }\end{array}$ & $64 \%$ & $26 \%$ & $10 \%$ \\
\hline 3. & $\begin{array}{l}\text { I am Jordanian because I belong to a Jordanian } \\
\text { tribe }\end{array}$ & $77 \%$ & $23 \%$ & - \\
\hline 4. & $\begin{array}{l}\text { I am Jordanian because I am committed to the } \\
\text { customs and traditions of Jordanians. }\end{array}$ & $68 \%$ & $26 \%$ & $6 \%$ \\
\hline 5. & $\begin{array}{l}\text { I am Jordanian because I am committed to } \\
\text { Jordanian laws. }\end{array}$ & $69 \%$ & $31 \%$ & - \\
\hline 6. & $\begin{array}{l}\text { I am Jordanian because I belong to the Jordanian } \\
\text { State and regime. }\end{array}$ & $86 \%$ & $10 \%$ & $4 \%$ \\
\hline 7. & I am Jordanian because I wear Jordanian costume. & $58 \%$ & $40 \%$ & $2 \%$ \\
\hline 8. & $\begin{array}{l}\text { I am Jordanian because I have lived most of my } \\
\text { life in Jordan. }\end{array}$ & $93 \%$ & $5 \%$ & $2 \%$ \\
\hline 9. & $\begin{array}{l}\text { I am Jordanian because my name, my tribe's name } \\
\text { and title are Jordanian. }\end{array}$ & $75 \%$ & $21 \%$ & $4 \%$ \\
\hline 10. & $\begin{array}{l}\text { I am Jordanian because my upbringing and } \\
\text { education are Jordanian. }\end{array}$ & $88 \%$ & $9 \%$ & $3 \%$ \\
\hline 11. & I am Jordanian because my dialect is Jordanian. & $66 \%$ & $27 \%$ & $7 \%$ \\
\hline 12. & $\begin{array}{l}\text { I am Jordanian because my shape and appearance } \\
\text { show that. }\end{array}$ & $40 \%$ & $52 \%$ & $8 \%$ \\
\hline
\end{tabular}

The table indicates some important indicators of the perception of the formation of Jordanian youth's identity. $93 \%$ of the subjects believed that the geographical site connected with living, land and the state is what makes them identify themselves by the Jordanian identity. $88 \%$ of the subjects connected identity with its value and cultural dimension because Jordanian identity is reflected in the individuals' upbringing and the formation of an identity they perceive. $86 \%$ of the subjects connected identity with the constituent of the state and specifically the ruling regime which may gather most Jordanians as being the most prominent preserver of the existence and form of Jordanian identity and the existence of the Jordanian state as a whole. However, the tribal dimension was evident in the formation of identity as it had a percentage of $77 \%$ of the subjects' responses. The tribe is the real protector of Jordanian existence as it is a basic component of the formation of identity and its perception. 
The Jordanian individual concentrates too much, when introducing himself, on the name of his tribe, a behavior which is common among the individuals of Jordanian society. The individual is called by the name of his tribe rather than by his first name. Language and dialect had a percentage of $66 \%$ as important in the formation and strengthening of the perception of identity (Joseph, 2007).

The subjects were asked about how they defined their identity to other people (I am Jordanian, I am an Arab, I am Muslim or Christian) put them in order according to priority.

The results of this question came with a percentage of $62 \%$ to the advantage of regional state with the tribal constituent, then $21 \%$ to the advantage of national identity and finally $17 \%$ to the advantage of religious identity. This is a real reflection of the retreat of national and religious feelings as constituents which have become old for Jordanian youth because the sensation of strength and achievement of interests cannot be obtained without tribal membership which is connected with the Jordanian State.

\section{Conclusion:}

Stiwart Hall says that there is now an essential debate among the people of social theories in regard to the issue of identity. The debate is basically about the idea which states that the national identity which formed, for a long-time, a base for the stability of social space is now about to disappear, the fact which requires new identities that make the modern person in his quality a unified self in a state of fragments (Hall, 2008: 137).

Identity does not represent a cultural or societal fact that has the quality of perfection, but it is an essential value existing by man's understanding, perception and capability to solve his life problems (Bssaissou, 2005). The Jordanian citizen, as other members of the peoples of the Arab world, lives a state of frustration resulting from the nature of circumstances he has lived through the formation of the weak states of the Arab world ever since the end of colonization up till the present time. There have been doubts about the national and religious constituent of identity because the common factors of the formation of national or religious identity have been symbolically shocked in the Arabic sensation as a result of the failure of the Arab national constituent followed by the religious one. This has been evident in the failure of solving Arab common issues and problems because actions and events are stored in memory to be recalled in similar subsequent situations (Zayid, 2006).

In light of the absence of an Arabic or Islamic unanimous or even relative resolution to solve these problems, these internal Arab disputes, religious differences, sects and different approaches in intellectual basics and gathering crowds, the fact which has resulted in double standard sensations toward these issues. The Palestinian cause which used to form the central one for the Arab crowds, has changed to become one of the constituents of separation, between those who are for or against peace. Then comes the belief religious dimension which has changed into political fights between sects and currents that are called Salafi, Liberal, Sunni And Shiite consequently changing the concept of identity to an unsensed symbol of the Arab self.

When identity is of a national nature to form the personality and prevalent pattern of life in a certain society connected with a common heritage of language, history, religion and traditions (Ba Abadin, 2007), Jordanian youth are a reflection of this state. The Jordanian, 
since the establishment of the state till the beginning of the nineties of the past century, was one of the most sensitive people of their national identity, as being Arabs first and then Muslims, but the vital transfers which have affected the structure of this identity make them as other Arab peoples confined toward the state as it closely expresses their aspirations and interests, However, belonging to the Jordanian identity, in its regional dimension, is subordinated to the tribal constituent which is the most prominent one of the state, The Jordanian state is based on tribal constituents that share power with the ruling regime even if this is not directly stated, the fact which has reinforced the tribal constituents that is the family dimension in the symbolism and formation of the Jordanians identity .

He belongs to a family, to a tribe and he is a Jordanian who belongs to the state, not by his individual quality but by his tribal constituent. It may express a healthy state of the sensation of identity even if it is in narrow frames.

In spite of the political divisions in all issues, the Jordanian narrow identity was stated by Nadeem (2012) in the case of Palestinian identity.

Given that the third world countries suffer from dangerous problems and crises which threaten their national unity, at the top of which is the crisis of national identity relating to the formation of a common sensation among the one society individuals (AL-Zeid, Rushdi, Amarah, 2007:9), we can say that Jordanian youth have a clear confusion in the identity constituent which they perceive.

They prefer to identify themselves as Jordanians, but at the same time they prefer to link this identity to the national Arabic sensation and they are Muslims or Christians because they do not want to get detached from that.

Consequently, Jordanian youth do not actually live in a state of identity crisis but in a state that may be called a re-formation of identity. It may be a healthy one required by the present stage in which the concepts of the globalization have been strengthened toward being restricted to the narrower structures in society, as being, according to the individual's beliefs, capable to protect them and their cultural constituent. The evidence in Jordanian society is the fast running toward the idea of heritage revival and the restoration of some customs that have nearly vanished to re-appear in a modern society .

The fear of the loss of the sensation of belonging to the self, the state, then to Arabism and religion pushes toward minimizing the circle of the basic then the tribe and the family to make the individual feel the re-formation of his individual and collective existence 


\section{References:}

- Tony Bindit; Lowrance Grossbirg; Migan Morriss (2010), New Opening Terms, Dictionary of the terms of culture and society, Translated by Sa'eed AL-Ghamidi. Arabic Organization For Translation, Beirut, Lebanon, Ed.1.

- Harlmbiss and Hallborn, 2010, Sociology of Culture And Identity, Translated by Hatim Muhssin, Dar Keeway For Printing and publication, Ed.1, Damascus.

- Ghassan, Muneer (2002), Marks, Indicators And Measure Of National Identity, National Identities, International Society And Media, Dar AL-Nahdhah AL-Arabiyyah, Beirut.

- Banani, Dar AL-Hakeem, The Body And Self-Identity, The World Of Thought Magazine, No.4, Vol.37, April-June, 2009, National Council For Culture and Arts, Kuwait

- $\quad$ Al-Dahiri, Saleh Hassan And Others (1998), General Psychology, Dar Hamadah For Publication.

- $\quad$ Shiltz Dwan (1983), Personality Theories, Dar Al-Nahdhah AL-Arabiyyah, Cairo.

- $\quad$ Dhahir, Ahmad Jamal (1985), Social And Political Upbringing in the Arab World with a Field study of the Northern Region of Jordan, AL-Manar Bookshop, Jordan.

- $\quad$ National Jordanian Charter, 1991, First chapter, Fifth.

- Al-Afeef, Ahmad Khalaf and Saleh, Muhammad Qassem (2006), National Education, Amman, Dar Jareer for Publication and Distribution.

- $\quad$ Mahafzah, Ali; Abdulrahman, Isma'eel, Abdulhei, Waleed (2006), Amman, Dar Jareer for Publication and Distribution.

- $\quad$ Mubeidheen, Muhannad, 6/8/2010, Jordanian Al- Dostour Newspaper, Is our Identity Unified Before we Ask Equality?

- Ghadnar, Antony with the help of Kadin Brossal (2005), Sociology with Arab Introductions, Ed. 4, Translated by Fayiz Al-Sabbagh, Beirut, Arabic Organization for Translation.

- Al-Jureibee', Muhammad Abdullah, An Introduction To The Study of Jordanian Identities, A Sociological Study of the Case of Jordanian Identity, 2012, http://www.thoriacenter.

- Ma'loof, Ameen (1999), Deadly Identities (Readings in Belongingness And Globalization), Translated by Nabeel Muhssen, Ed. 1, Ward for Printing Publication and Distribution: Damascus.

- $\quad$ Busseisso, Abdulrahman, Culture and Identity or Culture and the Battle of Defending Identity, Ministry of Culture, Gaza, 2005, The Project of Strategic plan for Natural Culture.

- $\quad$ Ba Abbad, Sa'eed Abdulrahman (2007), Cultural Identity in the Testbooks of Social Studies in the Higher Basic Education Stage in Yemen Through the Analysis of their Content and the Views of their Teachers, Unpublished Master Thesis, Hadhramoat University, Yemen.

- $\quad$ Al-Zeidi, Rasheed Amarah, The Crisis of Iraqi Identity Under Occupation, The Arabic Magazine for Scientific Science, No. 14, 2007, The Arabic United Studies Center, Beirut, pp. 9-30. 
- Joseph, Jhons (2007), Language and Identity, Ethnic Religious Nationality, Silsilat Aalam Al-Ma'rifah, No. 342, The National Council for Culture and Arts, Kuwait.

- $\quad$ Zayid, Ahmad (2006), The Psychology of Relationships Between Groups, Issues in Self-Identity and Self- Classification, Sisilet Aalam Al-Ma'rifah, No. 326, The National Council for Culture and Arts: Kuwait.

- $\quad$ Rowhan, Nadeem, National Palestinian Identity and Political Solutions, Palestinian Studies Magazine, No. 89, 2012, Palestinian Studies Organization, Beirut, pp. 7-19.

- $\quad$ Khalid Fayyadh (2010), Digital Pyramid: Jordan Where to? National Identity A Future Prospects http://ahramonline.org.eg. 